\title{
Papers
}

\section{Risk management strategy: A practical guide for risk awareness and its cause and effect on project deployment}

\begin{abstract}
Abby De Millo
is Director of Technology for Scholastic, for whom she establishes and directs the operational and technical strategy of both content management and digital asset management systems. She is the executive project lead for the redevelopment of Scholastic's enterprisewide digital asset management program as well as expansion and redevelopment of e-Scholastic's web content management practice. With over 20 years of industry experience in directing digital and e-business operations, web application design and usability design and testing. Abby has established herself as a leader and expert at creative business solutions.
\end{abstract}

Keywords: planning for risk, resolving risk, monitoring risk, risk control, tracking, control plan

Abstract What causes us to naturally avoid the pitfalls of everyday life, yet be so out of touch with the pitfalls of project management? This practical guide defines risk management and outlines the strategies for risk avoidance, while helping project managers understand the value of incorporating a few simple risk management steps in their project planning.

\section{INTRODUCTION}

We all know that in life, there is inherent risk in everything we do. Most of us go through the motions of protecting ourselves from risk every day without consciously saying to ourselves, "this is a potential threat to my wellbeing and this is what I'm going to do to minimize this threat". We stop at stop signs, look both ways before crossing the street and buckle our seat belts when we're in our cars. We don't draw up a plan for these actions because we have learned to integrate natural risk awareness into our everyday behavior.

So why, when managing technology projects, does planning for risk seem like such an outlandish idea? A logical progression of thought is that if we can be taught to look both ways before crossing the street, then we should be able to learn how to look both ways while planning projects. Yet nine out of ten project leaders do not incorporate risk avoidance methods into their project planning. Those that do, frequently end up cutting valuable risk planning steps from the project due to scheduling pressures. The results can be disastrous - inadequate risk management planning has ended up costing North American companies billions of dollars in failed implementations over the years.

\section{WHAT IS RISK MANAGEMENT STRATEGY?}

Risk management strategy is a formal program that can help you do what you normally do in everyday life. It helps you to anticipate, articulate and plan for problems. Setting up a formal strategy for risk avoidance is critical to the success of technology projects because there are so many variables that could affect the outcome of every project phase that it is simply impossible to "wing it" and expect to land within a reasonable variance of project scope and budget. The results can be visualized as a game of dominoes. One unplanned critical risk can set into motion a systematic failure - like a chain reaction - which bumps into each dependency until the entire project fails.

The ability to manage risk effectively is pivotal to the success of any large-scale 
technology project, and asset management projects are no exception. Indeed, asset management deployment introduces different types of risks and dependencies not usually a part of business application projects. Risks unique to asset management projects include integrated desktop workflows that introduce multiple platforms and operating systems (eg publishers who are in the middle of a lengthy migration from $\mathrm{Mac} \mathrm{O} / \mathrm{S} 9.2$ up to Mac O/S X may introduce compatibility issues); or downloading huge graphic files from a web application (which introduces network, browser and file format issues).

Whether you are building an asset management application from the ground up or configuring and customizing an existing product, risk management should be a natural step in the pre-planning phase. The level of risk multiplies if you have multiple users, dependent workflows, connection to product or customer databases or are integrated with third-party applications. For enterprise-level asset management projects, other specific risk variables can include: asset level complexity, rights level complexity, data updates, access level security issues, integrated workflow variables, taxonomy and data integrity.

Are you worried yet? Relax! If you follow a few simple and proven techniques for controlling what may seem like a self-replicating list of project risks, you will be well on your way to a successful roll out.

Risk management techniques can be broken down into two methods - assessing and controlling risk. Assessing risk involves formally identifying risk variables during the project scope (or pre-planning phase) and controlling risk builds planning and resolution into the project. During the initial phases of project planning, the project team has the opportunity to analyze the risk variables and design and plan for alternative solutions to help mitigate risk during project implementation.

\section{WHY IS SUCH A FORMAL PROGRAM OF RISK MANAGEMENT NECESSARY?}

OK, so now we know what risk management strategy is - but why do we need to follow such a formal program?

Well, for one thing, history has proven time and again that any project not incorporating formal risk management methods into planning stands a far greater chance of failing than projects that do include well considered risk planning techniques.

North American companies are estimated to have spent more than $\$ 1$ trillion on IT deployments and surrendered nearly $\$ 300$ billion on late, overbudget, or failed implementations during the past three years (1999-2001). These projects failed not for lack of money or technology, but for lack of skilled project management and adequate risk management practices and because fewer than 20 per cent of Global 2000 companies have IT organization risk managers. ${ }^{1}$

Formal risk management methods are necessary because they help us make more intelligent decisions. Not everything can be anticipated, of course, but by identifying the cause and effect of key risk factors well ahead of time, big problems become manageable. Having a "Plan B" before you are confronted with the problem is always a good thing.

Risk management methods help us to understand and control project risks that are caused by:

- the occurrence of unwelcome generic events;

- the occurrence of unwelcome technical events;

- a change in business direction or requirements;

- a change in project stakeholders or project team members.

Risk management methods help to prevent project failure by controlling project change and project cost. Risk management methods also help us to evaluate the impact to project interdependencies - other elements of the project that might or might not be out of your direct control, but that are affected by delays and changes to the core project.

Ideally, if intelligent risk management methods are followed during the life of your project, no one will notice. But if you choose to ignore this discipline and problems come up (as they always do), then you will have a large and unwelcome audience witnessing your team scrambling to resolve the issue or issues - putting your project off track and calling into question your (or your team's) credibility. 
Key benefits for practicing solid risk management methods include:

- avoidance of unnecessary project delays;

- ensuring the achievement of key organizational goals;

- enabling the smooth running of an information system;

- avoidance of unnecessary project costs;

- ensuring that the right people are controlling the right parts of the project;

- enabling a tightly controlled quality control standard.

\section{CAUSES AND TYPES OF RISK}

In a survey conducted by Coopers \& Lybrand, ${ }^{2}$ the three major causes contributing to overall project risk were identified:

- Inadequate use of risk management controls. Risk management controls are the materials and processes necessary to control risk (ie change order forms or risk escalation protocol). Using risk management controls requires discipline - they are meaningless if no one uses them. And as Oprah Winfrey said (referring to exercise and diet) during a recent interview with Wynonna Judd, "Funny thing about discipline ... once you start doing 'the thing', you have discipline!'3 Once you begin using "the things" called risk management controls, you'll find that you will be able to track the history of changes and decisions and you will be able to address problems and issues more efficiently.

- Insufficient understanding of business issues. Lack of understanding of business issues is the result of not fully analyzing the business before you begin planning for your project. Skipping over or undermining the importance of a thorough business analysis is one of the most common pitfalls of project management. Only by asking the questions will you be able to fully understand the issues that end-users face daily user interface, workflow or business issues can all be flushed out and categorized into a list of business needs that will help to shape your project.

- Too little accountability.

Project meetings can only be effective if everyone sitting around the table has a valid part to play in the success of the project. Team members or business stakeholders who don't feel accountable for decisions that are made are like anchors weighing down your project, forcing you and the rest of your team to carry them along on your lonely journey. Higher-level executives who are not effective project stakeholders can actually reverse the good results of your project by inhibiting corporate buy-in, resisting change and limiting your ability to make well-informed decisions.

There are two general types of risk - generic and project-specific.

Generic risks are risks that are common to all types of projects. Some are caused by basic human nature; others are the result of human error such as bad human resource planning.

Generic project risks include: misunderstanding business objectives (usually caused by not listening to analysis results or not conducting an effective business analysis); miscommunication of business and project goals (caused by not articulating what the project results will achieve for the company); and losing key personnel (caused either by bad personnel management or by not listening or planning for personnel needs). Mitigating the risk of losing key personnel during a critical part of a project could be as simple as coordinating vacation schedules, or knowing your team members well enough to know who will be getting married during the project lifecycle.

Project-specific or technology-driven risks are caused by specific project interdependencies such as error in code development or delays in development of a middleware application.

To properly identify project-specific risks, it is necessary for the project lead to first break down the individual components of the project. By laying out all of the elements (or constructs) of the project, even if you don't yet have all of the detailed elements in place, you can better visualize the types of problems you might face when you get to that point in the project. As an example, while planning out Scholastic's asset management project, we identified that a connection to our corporate database was one of the key components that needed to be in place in order to dynamically update our product information. The project, MQSI, was being run by another project team and we had no control over their project schedule. For this reason, we needed to identify the dependency as a critical 
risk to our project. So, we minimized the project risk by coming up with a 'Plan B' that involved a nightly update of all necessary data files to the asset management system. Not a dynamic solution, but a good alternative that would keep our project on track if the WebSphere MQ piece was not ready in time.

\section{WHAT ARE THE MAJOR COMPONENTS OF RISK MANAGEMENT PLANNING?}

Good risk management planning does not have to be complex (complexity, in fact, is related to the complexity and interdependencies of your project) but it does have to embrace two phases - assessment and control.

\section{The assessment phase}

During the assessment phase, risks that will have specific adverse effects on the project are identified. Being able to articulate the risk event and the loss associated with the risk event, such as loss of time, additional expenses or loss of project control is the first step in this process. Identification of risks can be accomplished during the pre-planning phase by conducting a one-day or half-day team meeting where everyone has a forum to review the high-level project plan and can freely discuss the "what if" scenarios at every stage of the project.

Once generic and specific project risks are identified, the team needs to analyze and assign each risk a "risk factor" priority number. Sound simple? Not if you are serious about prioritization. This is the trickiest task of the assessment phase. If all perspectives are not considered regarding the risk, it negates the value of the entire risk management process. To prioritize effectively, is the best idea to take into account the two common methods of risk analysis - quantitative and qualitative risk analysis.

Quantitative risk analysis is the method of assigning metrics to specific risks and sorting by prioritization. An example of quantitative risk analysis is the cost associated with a risk such as losing key personnel. Recruiting costs (if you needed to hire new personnel) or consulting costs (if you needed to fill in the position with an outside consultant) could bump up the risk in priority. Time loss is another quantitative factor that moves a risk up in priority.
Project management would be a cinch if quantitative analysis methods alone provided us with all of the tools needed to fully assess risk impact to a project. This is only one half of the risk analysis equation, however.

The other half of the equation is qualitative risk analysis. Qualitative risk analysis employs a more holistic approach to mitigating risk.

During this method, logical arguments are made and risk impact results are balanced with business objectives and needs. Business assumptions and applied business risks are factored into the analysis and help to give a broader picture to the prioritization process.

Going back to our "loss of key personnel" risk example, if we were only to prioritize this risk by quantifying methods, the risk would be level one if recruiting costs were significant. But after discussion, the team concludes that with a little creative resource allocation, another team member can step into the key role during the project lifecycle - the priority rating drops down, and the risk is no longer considered critical.

Once a comprehensive list of risk events and risk losses (or project effects) have been articulated, they need to be documented in a project risk matrix (see Table 1).

A project risk matrix helps the project team to categorize the levels of risk and discuss and prioritize the likelihood of the risk occurring during the life of the project. The project risk matrix is the first "tool" to help you quantify unknown events, and is based on rating numbers (quantitative) and logical arguments (qualitative). Quantifying events and issues helps you to visualize and construct resolutions and alternative courses of action to mitigate risk. The last three columns of the risk matrix: resolution, solution delivery date and cost changes will be filled or confirmed during the control phase.

\section{The control phase}

During the control phase, decisions and steps are taken to either avoid risk, or reduce negative risk impact on the project. The prioritization of the risk will help to determine the degree of risk control required to avoid or minimize this risk.

Avoiding a resource risk, such as the loss of the project lead, might only require an identification of the "next in command" who will be able to assume responsibilities should the 
Table 1: Project risk matrix

\begin{tabular}{|c|c|c|c|c|c|c|}
\hline $\begin{array}{l}\text { Issue } \\
\text { ID\# }\end{array}$ & $\begin{array}{l}\text { Broad issue } \\
\text { description }\end{array}$ & Specific issue description & $\begin{array}{l}\text { Priority rating } \\
\text { (solution } \\
\text { workaround) }\end{array}$ & Resolution & $\begin{array}{l}\text { Solution delivery } \\
\text { date (target) }\end{array}$ & Cost charges \\
\hline 123 & $\begin{array}{l}\text { Connection to } \\
\text { remote DB }\end{array}$ & $\begin{array}{l}6 \text { months delay in middleware } \\
\text { product development. }\end{array}$ & 1 & $\begin{array}{l}\text { On-site interim solution- } \\
\text { workaround. }\end{array}$ & 30 business days & $\$ 20,000$ \\
\hline 234 & $\begin{array}{l}\text { Resource } \\
\text { allocation }\end{array}$ & Project lead resigned. & 3 & $\begin{array}{l}\text { Tech team lead filling in } \\
\text { until new hire takes place. }\end{array}$ & 14 business days & $\begin{array}{l}\text { Recruitment cost } \\
@ 15 \% \text { base salary }\end{array}$ \\
\hline 456 & $\begin{array}{l}\text { Business } \\
\text { requirements }\end{array}$ & $\begin{array}{l}\text { Additional critical requirement } \\
\text { affecting functional } \\
\text { specification. }\end{array}$ & 1 & $\begin{array}{l}\text { Functional matrix needs to } \\
\text { be revised to include } \\
\text { additional system } \\
\text { functionality. } \\
\text { Development schedule } \\
\text { needs to be reworked. }\end{array}$ & $\begin{array}{l}30 \text { business days } \\
\text { added to original } \\
\text { timeline }\end{array}$ & $\mathrm{N} / \mathrm{A}$ \\
\hline 567 & $\begin{array}{l}\text { User interface/ } \\
\text { usability }\end{array}$ & $\begin{array}{l}\text { Redesign of global navigation } \\
\text { buttons to be more user } \\
\text { intuitive. }\end{array}$ & 2 & $\begin{array}{l}\text { New graphics already } \\
\text { designed by in-house } \\
\text { designer. } \\
\text { HTML integration is next } \\
\text { step. }\end{array}$ & 2 business days & $\begin{array}{l}\mathrm{N} / \mathrm{A} \text { (integration } \\
\text { being handled by } \\
\text { internal team) }\end{array}$ \\
\hline
\end{tabular}

project lead be unable to finish the project. More complicated and higher-level risks, such as a major delay in a middleware development, might require separate meetings with other experts to determine a "Plan B" which would deliver the same results as the original plan but in a more controllable and acceptable timeframe.

My best advice to project leads is to always build in a 15-30 per cent contingency into your project budget to allow for unanticipated risk factors. The above example of the middleware development delay can be resolved by an interim solution, but at a cost to the project. If this risk is a top priority risk, then the additional dollars are justified. Because most budgets are compiled prior to the pre-planning phase (usually during the vendor selection or the project scope) the contingency percentage allows you the room to develop alternative solutions to mitigate project risk without having to re-justify costs.

The decision process can be more manageable if you remember that there are three decision paths:

- Risk avoidance by building risk management solutions. If the risk priority number is high, you will need to build either a concurrent sub-team to address a workaround or an alternative solution to avoid the risk altogether. If the risk does not occur, life continues as normal. If, however, the risk does occur, your team will be rehearsed enough to switch to "Plan B".
The decision path often requires additional time to be added to the project plan. From a few days to few weeks might need to be built into the schedule. If you are trying to expedite the project and feel that the additional time is unacceptable and might contribute to a missed rollout or launch date, I urge you to consider what your timeline will look like if you don't plan for highpriority risks in this way. Going back to our middleware dependency, had our team not provided an alternative solution (which added 30 business days to our plan) we would have missed our launch date by nearly one year. At the end of the project, not one business leader remembered that we needed one additional month to launch.

- Ignoring risk and proceeding with project. As a part of the risk identification process, your team should be free to anticipate any and all risks that can be imagined to have a negative impact on the project. The risk prioritization process helps categorize all risks as having high, medium and low negative impact. Statistically remote risks (such as a terrorist attack destroying your data center) can be ignored altogether because the probability of the risk occurring does not outweigh the cost in time or resources to prepare for risk avoidance.

- Stopping the project until risk can be resolved. Unanticipated risks or risks that are anticipated but not resolved during pre-planning stages might have a severe enough negative impact to your project that continuing with the project is in itself a business risk. Dramatic examples of this decision 
path would be a major network system failure or defective server hardware.

A wide variety of tools can be used during and after the core project, which will help any project lead resolve and monitor project risks. Here are a few of the tools that you absolutely need:

- Controlling change by a change control plan. A change control plan is simply a methodical way to keep track of changes to the core project plan. Documenting changes to the plan enables the project lead to monitor costs as well as decisions made over a wide range of time. A change control order can be a PDF file or Word document form that a member of your project team can fill out whenever there is a change (such as additional work or an additional component) to the original project scope. If you are using an outside development firm, a change control order can be used to monitor costs by comparison with the original proposal or project estimate.

- Resolving change by interim solution planning. Interim solution planning methods should follow the same course as your main project planning. A 30-day interim solution still requires a requirements-gathering phase, a functional specification phase, a redesign phase etc. The timeframe is usually condensed but the steps still need to be followed. The tool in this case is a project plan (I recommend using a project management application like Microsoft Project) that can be a sub-set of the master project plan.
- Project plan revision process.

As a project lead, you have to create a master project plan that is useful and tells the complete detailed story of your project (see, for example, Figure 1). A project plan should periodically be revised and redistributed to the project team during the life of the project. Interim solutions and changes to timeframe and requirements always need to be reflected in the master project plan. During the asset management project at Scholastic for instance, we went through several project plan iterations as risks came up and were resolved.

- Monitoring change by a project checklist.

A simple checklist of tasks associated with each project component helps you, as a project lead, keep daily track of the things your team members need to accomplish. As changes to the project occur, your project checklist will grow, but will always provide you with an ordered structure to what would otherwise be chaos.

- Reassessing risks through project phase audits. One of the most helpful tools I use is what I call "project phase audits". Project phase audits are short sessions ( $2-3 \mathrm{hrs})$ that are held in between the key phases of the project. During the Scholastic asset management project, we held project phase audits after the requirements gathering, usability, interface design, data analysis, data migration, and implementation phases.

During the audit meetings, the team takes a collective breather and reviews the previous phase. Problems that have occurred, both technical and

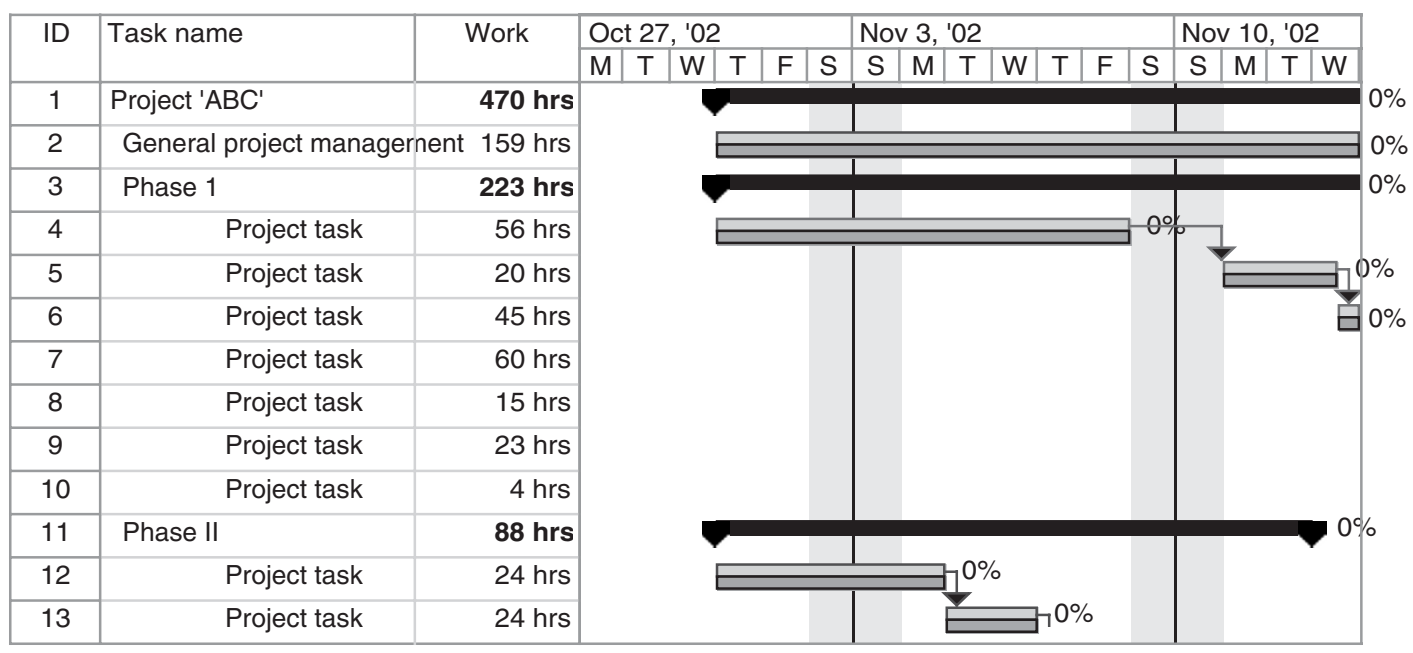

Figure 1: Project plan example 


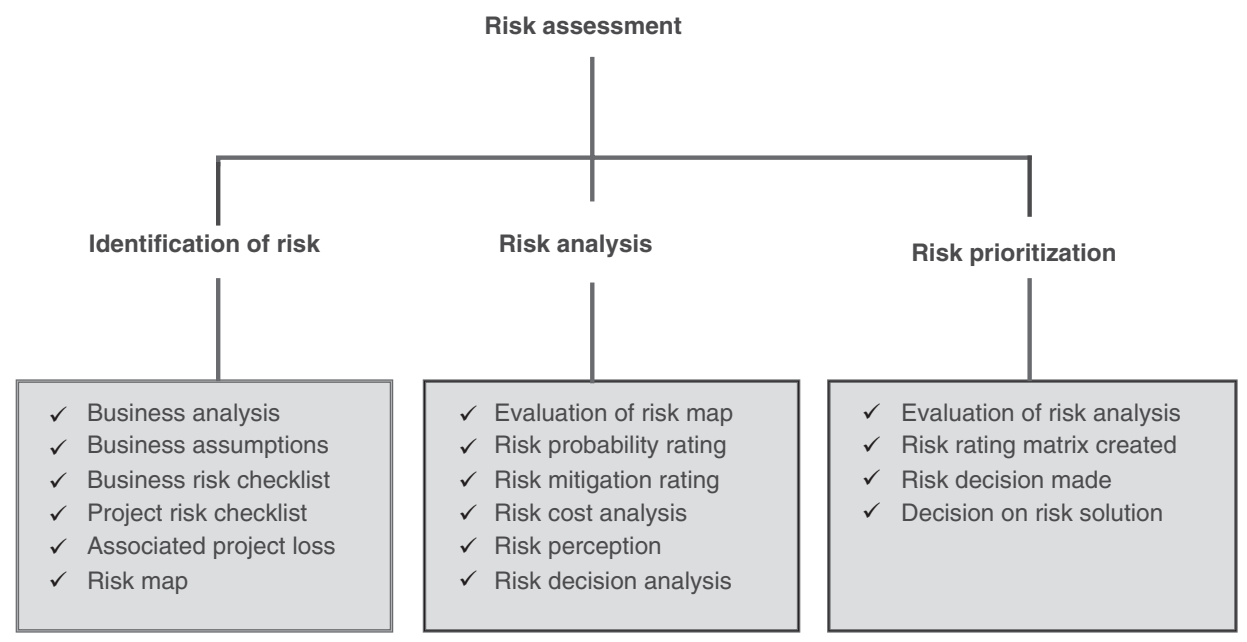

Figure 2: Risk assessment steps

Source: Adapted from Boehm (1991). ${ }^{4}$

team dynamic, are discussed openly and addressed before the project has a chance of going too far off-track. Steps are taken to resolve issues then, rather than letting things grow out of control. I worked on a project where we actually replaced team members as a result of a project phase audit - this resolved a major team dynamic issue that would eventually have put the entire project at risk had we not acted quickly.

- Continual review of project status through weekly project team meetings.

As boring as this sounds, the project lead has a responsibility to hold weekly team meetings during the project lifecycle and needs to keep a record of what was said at each and every meeting. Part of the final deliverables of every technical project is a collection of meeting notes that is a journal of dialogues and decisions made throughout the project.

An easy way to participate in the meetings and keep accurate meeting notes is to tape record each meeting so that someone can type up notes subsequently. Personally, I prefer typing up my own project team notes, because it forces me to think through the meeting discussions more carefully. At times, I have changed my decisions as a result of this process.

The summary Figures 2 and 3 list the key steps in the risk management process. This should be

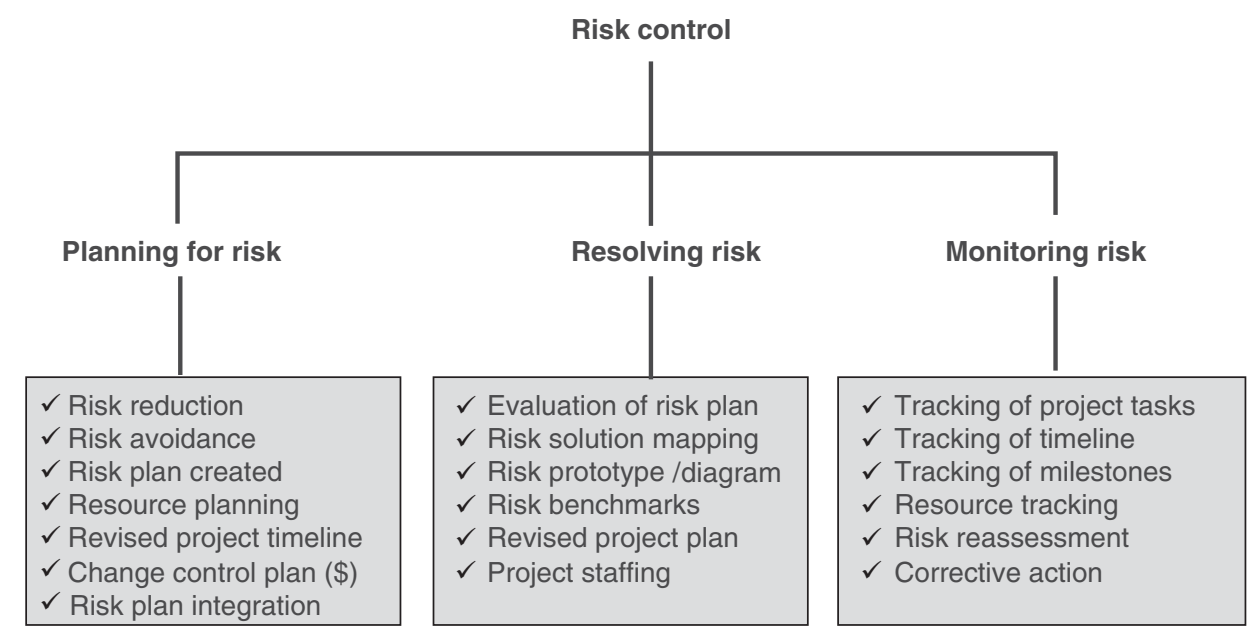

Figure 3: Risk control steps

Source: Adapted from Boehm (1991). ${ }^{4}$ 
used as a guide to help you learn to integrate this method of thinking into your project

management style. If you keep this list handy, in no time you will become a natural at risk mitigation.

Keep in mind that the risk assessment phase should be built into the project scope or preplanning of your project. Assessing risk while in the heat of the project is not an opportune time to be thinking of potential problems and is akin to looking up to see if there are any speeding cars while you are in the middle of crossing the street.

Identification, analysis and prioritization are all steps that take place during one- or two-day team meetings that involve all of the project stakeholders (internal or external clients, project team members, outside integration groups, the project sponsor). Getting both business and technical perspectives on what issues might become critical to project success is the key during the risk assessment team meetings. At the end of this phase, you should have a good list of risks identified, the risk causes and associated project losses identified, and an evaluation of the importance of mitigating or eliminating each risk.

Risk control, on the other hand, is not an encapsulated process. The utilization of risk control tools and methods for resolving risk take place during the entire project lifecycle. Planning for and resolving a critical risk might require a separate project plan or requirements-gathering process to occur, as in the example of the interim database solution. Because not all projects are created equal, the monitoring tools that have been described such as change control orders, formal project plans and resource tracking do need to be created and agreed upon at the start of the project - along with assigning the right team resources to "own" these tasks.

Remember, informed decision-making means intelligent decision-making!

\section{References}

1 Meta Group (2001), remarks by Al Passori, Vice President of the Meta Group, unpublished presentation.

2 Moules, J. (1996), http://www.comp.glam.ac.uk/ Teaching/ismanagement/riskman1f.htm.

3 http://www.oprah.com/tows/pastshows/200405/ tows_past_20040510.jhtml.

4 Adapted from Boehm, B. W. (1991) Software Risk Management: Principles and Practices, IEEE Software, Vol. 8,No. 1, January. Available to purchase at http://csdl.computer.org/cmp/mags/so/ 1991/01/s1032abs.htm.

\section{Further reading}

Carnegie Mellon Software Engineering Institute homepage: http://www.sei.cmu.edu/programs/ sepm/risk/.

Grey, S. (1995) Practical Risk Assessment for Project Management, Wiley, Chichester, UK.

Software Quality Association of Australia. 'A short report on Risk Management': http:// members.ozemail.com.au/ sqain/meeting_reports/ Risk_report.htm. 